\title{
Current Status and Future Prospects of GaN Substrates for Green Devices
}

\author{
Toshiro Doi* \\ Art, Science and Technology Center for Cooperative Research/Collaborative Research Division, \\ Kyushu University \\ 6-1 Kasuga Kouen, Kasuga, Fukuoka 816-8580, Japan
}

(Received September 26, 2012; accepted December 27, 2012)

Key words: bulk GaN single crystal, Na flux method, ammonothermal method, HVPE method, nonpolar GaN, semipolar GaN, polishing/CMP, diamond polishing, bell-jar-type CMP, damaged layer

Recently, single-crystal substrates applied to optoelectronic devices, such as sapphire, $\mathrm{GaN}$, and $\mathrm{SiC}$, have been attracting much attention for use in green devices. At present, they are mainly used for the blue-violet semiconductor laser that is applied as the light source of Blu-ray disc equipment. In the near future, it is highly likely that they will be introduced into white LEDs used for lighting and LCD backlight, power transistors to be used for power converters, and also into power semiconductors such as power diodes, leading to the rapid growth of the green device market involving $\mathrm{GaN}, \mathrm{SiC}$ and diamond. These single-crystal substrates are expected to serve as a trigger to realize a low-carbon and low-energy society, complying with the projected cutbacks of power and $\mathrm{CO}_{2}$ emission by 70 billion $\mathrm{kWh}$ and 40 million tons per year, respectively. This is why they are referred to as "green devices". In this paper, we will discuss the recent approaches that are in progress to develop new devices, taking GaN substrates as an example. Furthermore, we will review current problems and future perspectives for the most critical issue of realizing large substrates, as well as for the crystal growth method and manufacturing process that affect crystal quality.

\section{Introduction}

Recently, the use of single-crystal substrates of GaN and $\mathrm{SiC}$ for optoelectronic and electronic devices has become a hot research topic. From the application viewpoint, the use of GaN substrates is currently limited to blue laser diodes (LDs) in the optical pick-ups of Blu-ray DVDs. However, the market is expected to grow rapidly in the near future owing to the increased use of white light-emitting diodes (LEDs) for general

${ }^{*}$ Corresponding author: e-mail: doi@astec.kyushu-u.ac.jp 
lighting and display backlights, and power devices such as power transistors and power diodes for power inverters and converters. ${ }^{(1)}$

The major market driving force in the coming years will be white LEDs. The projected market for white LEDs is 900 billion Japanese yen (11 billion US dollars) in 2018, mainly driven by automobile headlamps, outdoor large-scale lighting, and camera flashes, which require high-power operation above $1 \mathrm{~W}$. GaN substrates are expected to be used in these high-power LEDs.

For power electronics, Si-based insulated gate bipolar transistors (IGBTs) and metaloxide-semiconductor field-effect transistors (MOSFETs) are currently in mainstream use; however, Si devices are reaching their theoretical limit in terms of power-handling capability. There is no doubt that next-generation power devices will utilize SiC and GaN. Particularly, the market for GaN-based power devices will grow considerably, resulting in strong demand for GaN substrates.

Concerning the current market and technology status of GaN substrates, Sumitomo Electric and Hitachi Cable are the market leaders, capturing approximately $90 \%$ of the market share. Sumitomo Electric, which has produced 2" (50 mm) GaN substrates, is now shifting toward the production of 6" substrates $(150 \mathrm{~mm})$ to reduce the substrate cost per unit area. In addition, they are collaborating with Soitec, a French company that has developed a smart-cutting technology, to develop a so-called engineered substrate, which consists of a very thin single crystal GaN film attached to a low-cost carrier wafer. ${ }^{(1)}$

On the other hand, Mitsubishi Chemical announced the expansion of its GaN substrate business, aiming to capture $40 \%$ of the market share in 2015 with over 100 times larger production capacity than the current capacity. They are also developing a new technology to reduce production costs. ${ }^{(1)}$ The positive attitude of these material manufacturers towards the GaN substrate business clearly shows confidence that the GaN substrate market will grow in the near future.

This article covers recent research activities on innovative devices that utilize GaN substrates, followed by a discussion on current issues associated with GaN substrates. In particular, major issues such as the expansion of substrate diameter, growth technology that determines the quality of substrates, and wafer processing will be discussed.

\section{Challenges toward Realizing Innovative Devices Using GaN Substrates}

Research on GaN-based LEDs became popular in the early 90s after the development of an AIN low-temperature buffer layer by Professor Akasaki and his colleagues, ${ }^{(2,3)}$ followed by a series of revolutionary breakthroughs by Professor Nakamura to attain InGaN blue LEDs. ${ }^{(4-6)}$ Nowadays, GaN-based blue, green, and white LEDs are widely used in cellular phones, traffic signals, large displays, illuminations, and so forth. Also, GaN-based laser diodes are used in pick-ups for optical disks in the latest computer games and videos. Additionally, white LEDs are expected to replace low-efficiency incandescent lamps and fluorescent lamps in the future. The energy savings from the adoption of solid-state lighting is expected to be $15-20 \%$ of the worldwide energy usage. Thus, white LEDs will contribute to the reduced consumption of fossil fuels and carbon dioxide emissions. ${ }^{(7)}$ This is why people call LEDs green devices. 
The demand for GaN substrates is expected to grow in the near future because GaN substrates can potentially realize innovative LEDs and power devices that significantly exceed the performances of current state-of-the-art devices. GaN substrates will improve the emission efficiency of blue LEDs, particularly for high-power devices with output exceeding $1 \mathrm{~W}$. It has been reported that $1 \mathrm{~W}$-class LEDs on GaN substrates have the potential to attain 1.5 times higher emission efficiency than those on commonly used heteroepitaxial substrates (e.g., sapphire). ${ }^{(8)}$ For power devices, GaN substrates also have many benefits including improved electric characteristics, increased breakdown voltage, and ease of designing devices having a favorable threshold voltage.

Moreover, GaN substrates present a new path towards achieving novel devices. Many researchers are now focusing on nonpolar and semipolar GaN substrates. For example, by choosing nonpolar or semipolar GaN substrates, laser diodes that emit pure green light have been achieved. ${ }^{(9)}$ Here, an overview of nonpolar/semipolar GaN technology is presented.

Blue LDs and LEDs are generally fabricated on the c-plane, which is a polar surface of $\mathrm{GaN}$. Since $\mathrm{GaN}$ is a polar material, it has an internal field associated with spontaneous polarization. In addition, InGaN, which is used for the active layers of optical devices, creates a piezoelectric polarization. The internal electric field caused by the spontaneous and piezoelectric polarization is aligned along the c-axis, i.e., the field is perpendicular to the structure of the active layers of conventional devices, causing a decrease in emission efficiency and a redshift of the emission wavelength. Figure 1 shows the crystallographic planes of GaN. Crystal planes such as the a-plane and m-plane, which are perpendicular to the c-plane, do not have an internal field along the plane normal and are thus called nonpolar planes. Similarly, crystal planes tilted from the c-plane have an internal field with limited strength, and are thus called semipolar planes. By utilizing these nonpolar and semipolar planes, optical devices can avoid the negative impact of the internal field. Removing the internal field across the active layers makes it easier to improve emission efficiencies and realize high-power emission in the green region.

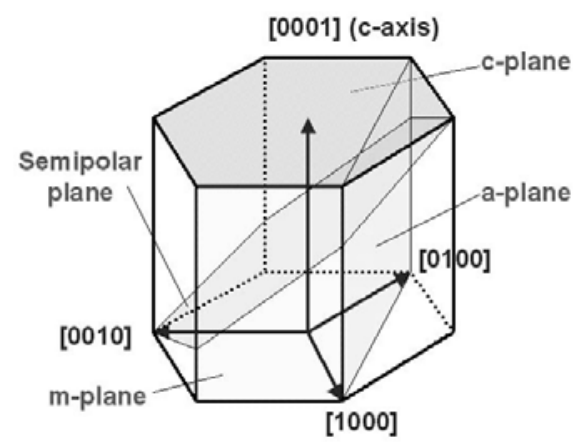

Fig. 1. Schematic drawing of crystal planes of GaN. The semipolar plane shown in this figure is one example among many semipolar planes. 
Professor Nakamura and his colleagues at the University of California, Santa Barbara (UCSB) made a significant contribution to the research on nonpolar/semipolar crystal growth and devices under the Exploratory Research for Advanced Technology (ERATO) program sponsored by the Japan Science and Technology Agency (JST). ${ }^{(10)}$ The lowdefect growth of a-plane, ${ }^{(1)} \mathrm{m}$-plane, ${ }^{(12)}$ and semipolar-plane ${ }^{(13)} \mathrm{GaN}$ was achieved through epitaxial lateral overgrowth, and an a-plane LED was demonstrated in 2005, ${ }^{(14)}$ as shown in Fig. 2. Also, freestanding m-plane 2" GaN substrates fabricated by HVPE were demonstrated, ${ }^{(10)}$ as shown in Fig. 3, and the group reported the first m-plane LED fabricated on such a substrate in 2005. (15) Owing to the high defect density (a threading dislocation density of $4 \times 10^{9} \mathrm{~cm}^{-2}$ and a stacking fault density of $1 \times 10^{5} \mathrm{~cm}^{-1}$ ), the external quantum efficiency (EQE) was limited to $0.43 \%$ at a drive current of $20 \mathrm{~mA}$ with an output power of $240 \mathrm{~mW}$ and a peak emission wavelength at $450 \mathrm{~nm}$.

Their pioneering work helped create the current research trend of nonpolar/semipolar GaN. A few years later, an m-plane LED with higher EQE (EQE 3.1\% at $20 \mathrm{~mA}$ for 1.79 $\mathrm{mW}$ and $435 \mathrm{~nm}$ ), ${ }^{(16)}$ an m-plane LED with higher output power (EQE $38.9 \%$ at $20 \mathrm{~mA}$ for $23.7 \mathrm{~mW}$ and $407 \mathrm{~nm}$ ), ${ }^{(17)}$ and a high-brightness semipolar LED (EQE 33.9\% at 20 $\mathrm{mA}$ for $20.6 \mathrm{~mW}$ and $411 \mathrm{~nm})^{(18)}$ were reported. Based on the nonpolar/semipolar device technology, Professor Nakamura founded a venture company called Soraa with two other UCSB professors and they released high-performance LED light bulbs in 2012 (Fig. 4). One important fact discovered through this research is that crystal defects, especially stacking faults, significantly deteriorate the emission efficiency of LEDs and LDs. Since nonpolar/semipolar GaN films directly grown on heteroepitaxial substrates contain high levels of stacking faults, most nonpolar/semipolar devices are currently fabricated on nonpolar/semipolar GaN sliced from a thick crystal of c-plane GaN grown by HVPE, which is typically free of stacking faults. This technological trend has led to strong

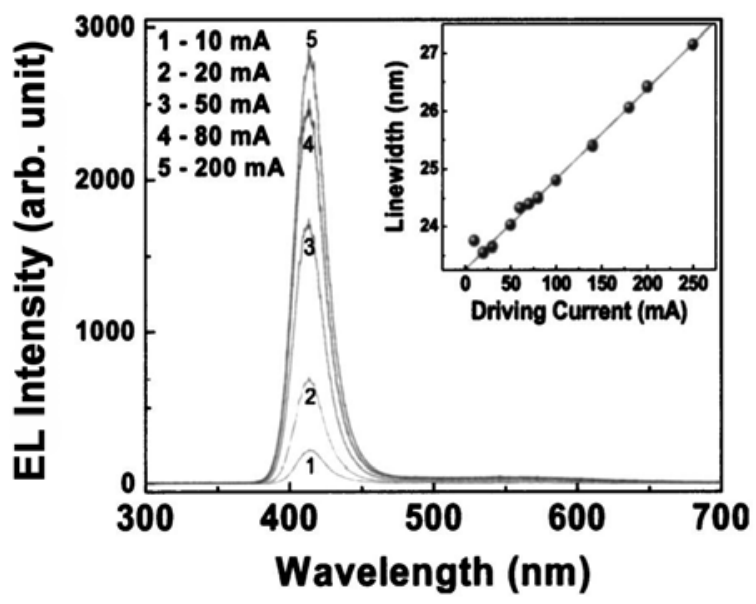

Fig. 2. EL spectra for different drive currents. The inset shows EL linewidth as a function of drive current. ${ }^{(14)}$ 


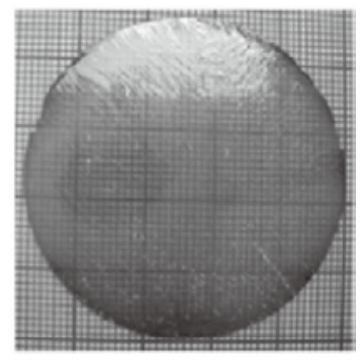

(a)

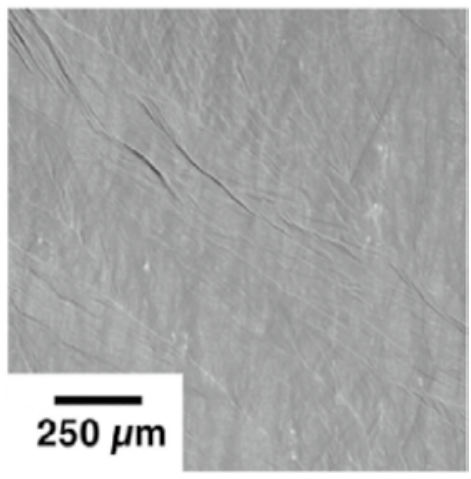

(b)

Fig. 3. Photograph of freestanding m-plane 2" wafer: (a) entire wafer and (b) surface morphology. ${ }^{(10)}$

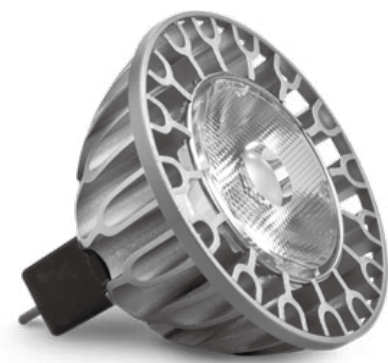

Fig. 4. An example of a high-performance LED light bulb released by Soraa.

demand for thick and low-defect bulk GaN crystals, from which large-area nonpolar/ semipolar GaN substrates can be sliced.

\section{Current Issues Regarding GaN Substrates for Green Devices}

Although bulk GaN substrates will bring about many benefits to green devices, there are a few issues regarding the commercialization of $\mathrm{GaN}$ substrates for use in highperformance, highly functional, low-cost devices. In this section, I will discuss the expansion of the substrate diameter, growth technology that determines the quality of substrates, and wafer processing.

\subsection{Impact of size expansion and current status}

Although $\mathrm{GaN}$ substrates are expected to significantly improve the performance of LEDs and power devices, they are currently only used for blue LDs and a very limited 
number of LEDs. This is not only because of the extremly high price of GaN substrates but also because of the limited size (2") of the available substrates, which is much smaller than those of other substrates. Owing to the size limitation, the lowest price for LED-grade GaN substrates is still more than 40 times higher than that of sapphire.

As explained above, the major substrate manufacturers are working on reducing the cost of $\mathrm{GaN}$ substrates through the expansion of the wafer size and improvement of the production process. For example, Sumitomo Electric has released engineering samples of 6" GaN substrates. They aim to first penetrate the huge LED market and then expand their sales into electronic devices. ${ }^{(19)}$ Their achievement has significant meaning because the 6" substrate size is as large as other competitive substrates used for LEDs and power devices. Considering the reduction of dead space with increasing space, the usable area of a 6" substrate is more than 9 times larger than that of a 2" substrate. Therefore, the expansion of the substrate size will enable the low-cost production of high-power blue LEDs and high-power, low-loss transistors through the reduction of the substrate cost per chip.

\subsection{Growth methods of bulk GaN}

\subsubsection{Ammonothermal growth of bulk GaN}

Figure 5 shows a schematic drawing of the ammonothermal method for bulk $\mathrm{GaN}$ growth. In this method, ammonia with a mineralizer is pressurized to 200-300 atmospheres by heating to approximately $400^{\circ} \mathrm{C}$. Metallic $\mathrm{Ga}$ or polycrystalline $\mathrm{GaN}$ is dissolved in the supercritical ammonia and GaN crystals are crystallized onto seed crystals. This is the same method used for the hydrothermal growth of quartz except for the substitution of water with ammonia. Several companies are trying to reduce

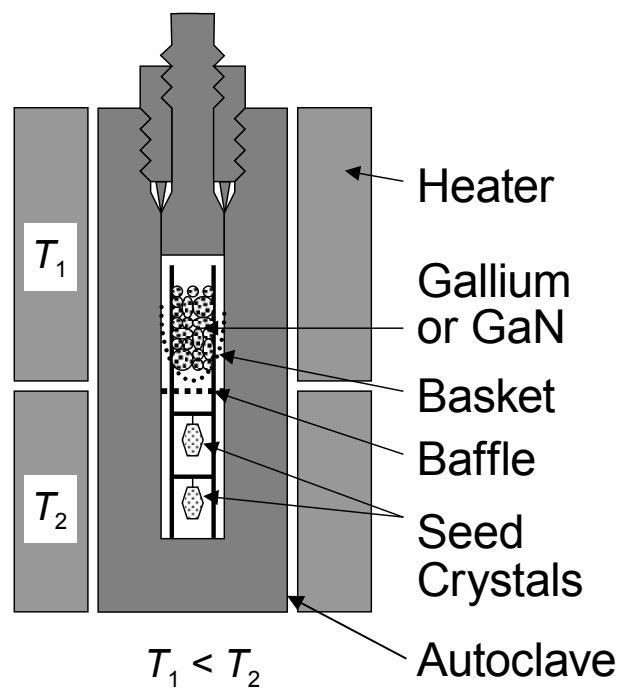

Fig. 5. Schematic drawing of ammonothermal growth. ${ }^{(10)}$ 
the production cost of $\mathrm{GaN}$ by the ammonothermal method because this method can be used to produce large crystals of GaN similarly to quartz. If large GaN substrates of various orientations can be sliced from large bulk GaN crystals, the substrate cost will be markedly reduced.

The ammonothermal growth rate is approximately $100 \mu \mathrm{m} /$ day, which is one to two orders of magnitude lower than that of HVPE. However, the ammonothermal method can be used to grow many bulk GaN crystals simultaneously, resulting in the lower production cost of $\mathrm{GaN}$ substrates. Because of this advantage, several domestic and foreign companies and research institutes such as Ammono, SixPoint Materials, Mitsubishi Chemical, Soraa, UCSB, Tohoku University, and the Air Force Research Laboratory are studying the ammonothermal growth of GaN. For example, Mitsubishi Chemical plans to start shipping engineering samples of GaN substrates produced by ammonothermal growth and shift the majority of its production from HVPE to ammonothermal growth. ${ }^{(20)}$

In addition to the advantage of scalability, the quality of the crystal grown by the ammonothermal method is excellent. ${ }^{(21)}$ For example, the full width at half maximum of the rocking curve obtained from X-ray 002 diffraction was reported to be $17 \mathrm{arcsec}$, with a lattice curvature radius of over $1000 \mathrm{~m}$. The etch pit density was reported to be $3 \times 10^{3}$ $\mathrm{cm}^{-2}$, implying a very low defect density.

There are several challenges to commercializing the ammonothermal growth of bulk $\mathrm{GaN}$ such as the expansion of the substrate size. In addition, the growth rate needs to be at the level of quartz growth and the transparency of the crystal should be improved. Although the coloring of the crystal is not a major problem for LDs and power devices, it decreases the emission efficiency of LEDs through optical absorption. However, SixPoint Materials, a spin-off company from UCSB, has reported the improved transparency of GaN substrates produced by ammonothermal growth (Fig. 6). ${ }^{(22)}$

Regarding the substrate size, the maximum reported size of a substrate produced by ammonothermal growth is 2". ${ }^{(23)}$ This is partly because of the difficulties in developing large-pressure reactors necessary for ammonothermal growth. At the moment, acceleration of the development speed is strongly required from device manufacturers. Table 1 summarizes the current status and future targets of ammonothermal GaN substrates.

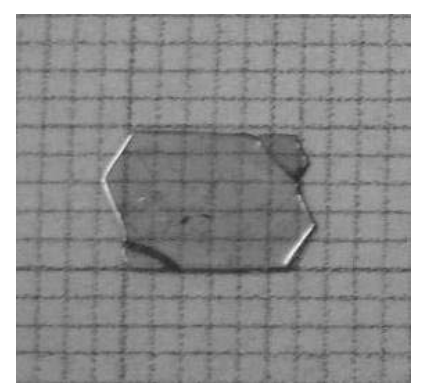

Fig. 6. Ammonothermally grown GaN substrate with improved transparency.(22) 
Table 1

Summary of current status and future targets of ammonothermal GaN substrates.

\begin{tabular}{lcc}
\hline Parameter & Current status & Future target \\
\hline Growth rate & $100 \mu \mathrm{m} /$ day & $500 \mu \mathrm{m} /$ day \\
Size & $2 \mathrm{in}$. & $6 \mathrm{in}$. \\
Curvature & \multicolumn{1}{c}{ Curvature radius over $1 \mathrm{~km}$} \\
Color & Slightly brownish/yellowish & Colorless \\
Defect density & \multicolumn{3}{c}{$10^{3}-10^{4} \mathrm{~cm}^{-2}$} & \\
\hline
\end{tabular}

\subsubsection{Na flux growth of bulk GaN}

The Na flux growth of bulk GaN was first reported by Professor Yamane at Tohoku University (24) and is now being actively studied by Professor Mori at Osaka University. ${ }^{(25,26)}$ As shown in Fig. 7, a GaN crystal is grown from a melt of $\mathrm{Ga}$ and $\mathrm{Na}$ in nitrogen under moderate pressure. Although the crystal quality depends on that of the seed crystals, a growth temperature higher than that used for ammonothermal growth allows the growth of higher purity GaN. In addition, the defect density is lower than that in HVPE-GaN and GaN substrates, and substrates with less bowing can potentially be obtained. For example, the oxygen concentration in a $\mathrm{GaN}$ crystal grown by the flux method is on the order of $10^{16} \mathrm{~cm}^{-3},{ }^{(27)}$ which is more than two orders of magnitude lower than that in ammonothermally grown GaN.

In addition, it was reported that the crystal became clear and transparent upon increasing the growth temperature or doping. Using this technology, the growth of largearea $\mathrm{GaN}$ through the coalescence of small nuclei on a circular seed (Fig. 8) and the expansion of the lateral dimension of needle crystals $^{(28)}$ have been proposed.

\subsection{Wafer processing of GaN}

It is obvious that the expansion of the substrate size will decrease the substrate cost per chip, but the overall substrate cost will still be higher than that of other substrates such as $\mathrm{Si}$. Therefore, it is important to introduce a new manufacturing process to reduce the production cost of substrates. Similar to $\mathrm{SiC}, \mathrm{GaN}$ can be categorized as a "hard material" because it is stable both chemically and mechanically; thus, it is crucial to develop appropriate methods of wafer processing. The flow of a typical wafer process is presented in Fig. 9. ${ }^{(29)}$

In the slicing step, a process that minimizes the slicing loss (kerf loss) is required because GaN crystals are much more expensive than other crystals such as Si. Of interest is the collaboration of Sumitomo Electric with Soitec for the development of ultrathin GaN substrates. They are applying the smart-cutting technology of Soitec to produce multiple ultrathin substrates from single GaN substrates. This is a breakthrough toward the significant cost reduction of 4-6" GaN substrates.

The edges of sliced GaN wafers are rounded by a beveling process because the small cracks generated at the wafer edges often cause the fracture of the wafer. After beveling, the wafer surface is polished by the process shown in Fig. 10. Among the polishing 


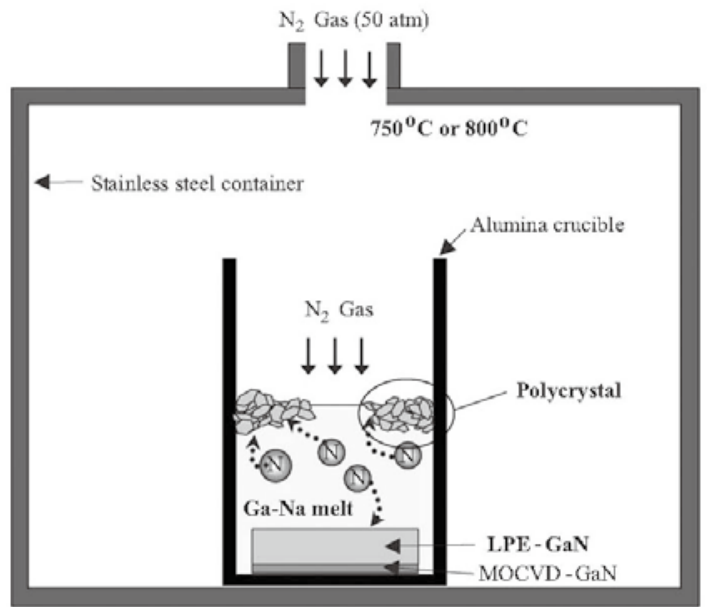

Fig. 7. Schematic drawing of flux growth of GaN.(26)

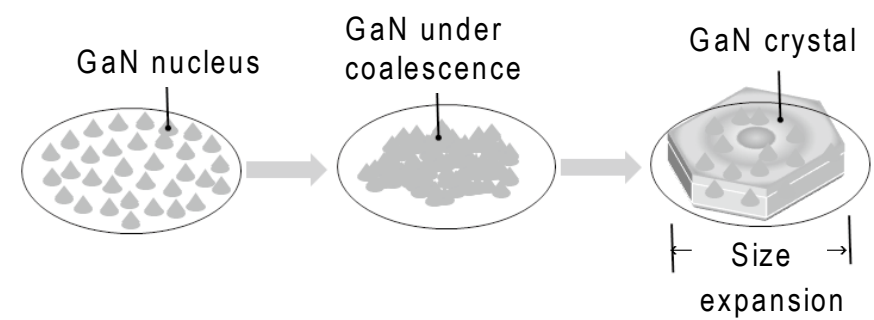

Fig. 8. Schematic drawing of enlargement of crystal size by flux method. (27)

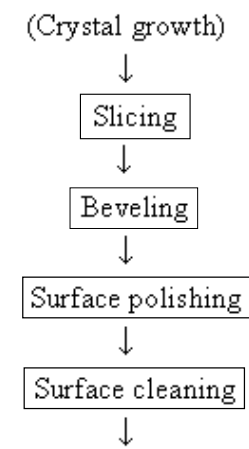

(Epitaxial growth)
First polishing (Diamond polishing) $\downarrow$ Second polishing (Nano-submicron/polishing) $\downarrow$ Surface finishing (Colloidal silica polishing/CMP)

Fig. 9 (left). Flow of typical process. ${ }^{(29)}$

Fig. 10 (right). Flow of polishing process. 
steps, the finishing step is critical in determining the device performance. In the case of $\mathrm{GaN}$, which is difficult to machine similarly to $\mathrm{SiC}$, the first step is mechanical polishing using a coarse diamond slurry $(1-3 \mu \mathrm{m})$ and a copper plate. In the second step, the surface roughness $(R a)$ is decreased to below a few $\mathrm{nm}$ using a submicron/nanodiamond slurry and a tin plate. ${ }^{(30)}$ The polishing mechanism is currently based on mechanical removal, which has a large removal unit. Therefore, the polishing speed is relatively high but the damaged layer still remains on the surface.

The last finishing step requires a lot of time. The finishing step typically uses colloidal silica (grain size of $10-20 \mathrm{~nm}$ ) on a soft artificial leather pad. ${ }^{(31)}$ This colloidal silica polishing/CMP aims to remove the damaged layer, scratches, and buried microcracks generated in the first and second polishing steps and attain an $\mathrm{Ra}$ of less than $0.1 \mathrm{~nm}$. However, it takes more than $10 \mathrm{~h}$ to achieve an undisturbed smooth mirror surface. Figure 11 shows time-dependent microscopy images of a GaN surface during colloidal silica polishing after diamond polishing as reported by Dr. Aida. ${ }^{(32)}$ As shown in this figure, it took more than $100 \mathrm{~h}$ to obtain the final smooth surface, which is more than 100 times longer than in the case of $\mathrm{Si}$. In $\mathrm{GaN}$ wafer polishing, more scratches appear even after the first layer of scratches vanishes. This is different from the case of other materials; thus, extra care is required for GaN wafers.

In the future, the development of higher efficiency polishing processes or the optimization of polishing conditions is required. The author and his colleagues have invented an innovative machining method using a bell-jar-type closed CMP system (Fig. 12), which can control the machining atmosphere, and are making progress in the highspeed machining ${ }^{(33)}$ of $\mathrm{GaN}$ wafers. Figure 13 shows the increase in polishing speed under high-pressure oxygen or air. ${ }^{(30)}$

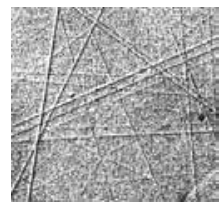

(a)

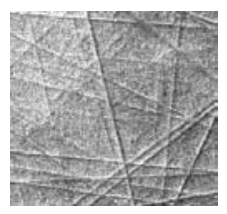

(d)

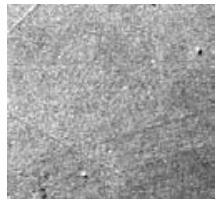

(b)

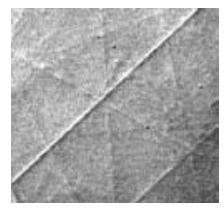

(e)

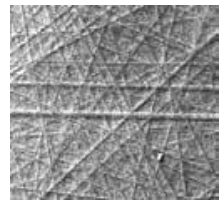

(c)

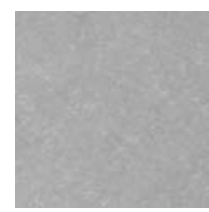

(f)

Fig. 11. Example of time-dependent microscopy images of GaN surface during colloidal silica polishing after diamond polishing:(32) (a) right after diamond polishing, (b) after $10 \mathrm{~h}$, (c) after $22 \mathrm{~h}$, (d) after $30 \mathrm{~h}$, (e) after $34 \mathrm{~h}$, and (f) after $150 \mathrm{~h}$. 

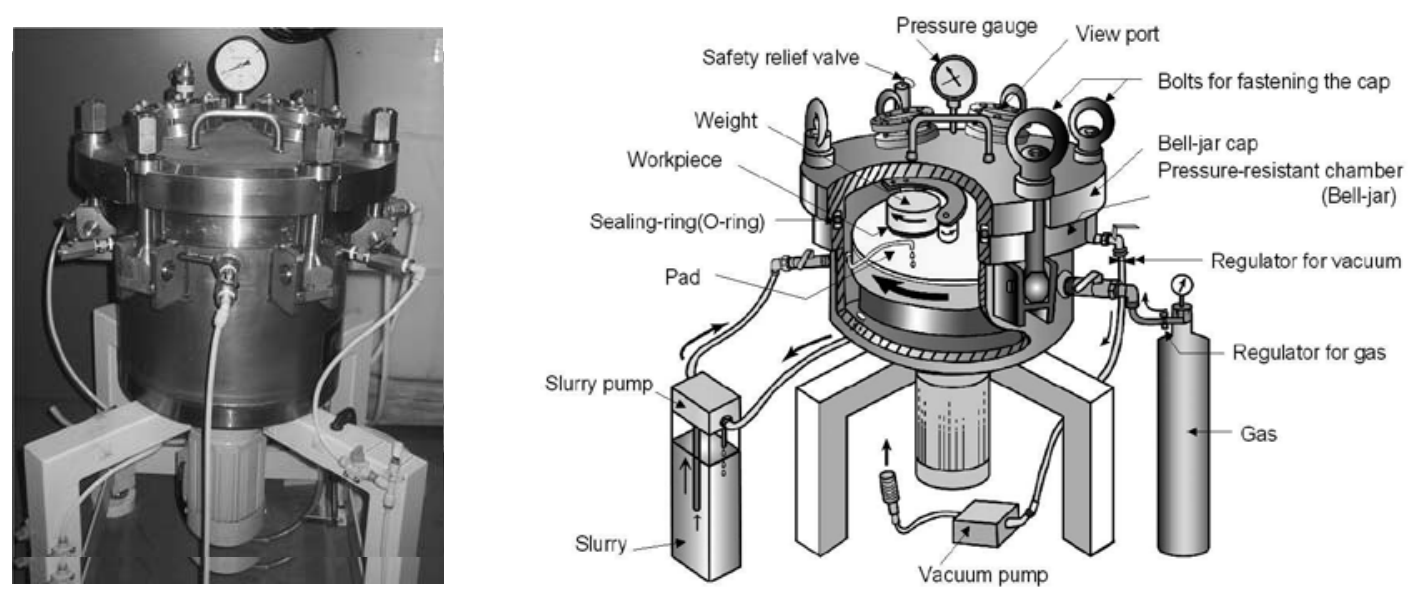

Fig. 12. A bell-jar-type closed CMP system. ${ }^{(33)}$

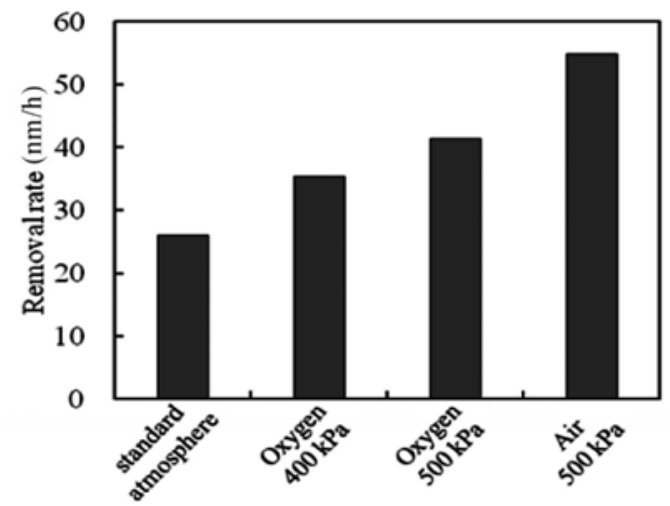

Fig. 13. Comparison of removal rate for different ambient gases and pressures. ${ }^{(30)}$

\section{Conclusions}

This article outlined the recent technological trends of GaN substrates from the viewpoint of applications in optoelectronic and electronic devices, which are considered as green devices. Although the use of GaN substrates is currently limited to blue LDs in the optical pick-up of Blu-ray DVDs, the GaN substrate market is expected to grow rapidly in the near future owing to their application to white LEDs for general lighting, display backlighting, and power devices for inverters and converters. Moreover, GaN substrates will be utilized for various sensors. Examples of such devices include GaN UV sensors (Fig. 14(a)) ${ }^{(34)}$ and gas sensors using GaN Schottky diodes (Fig. 14(b)). ${ }^{(35)}$ 


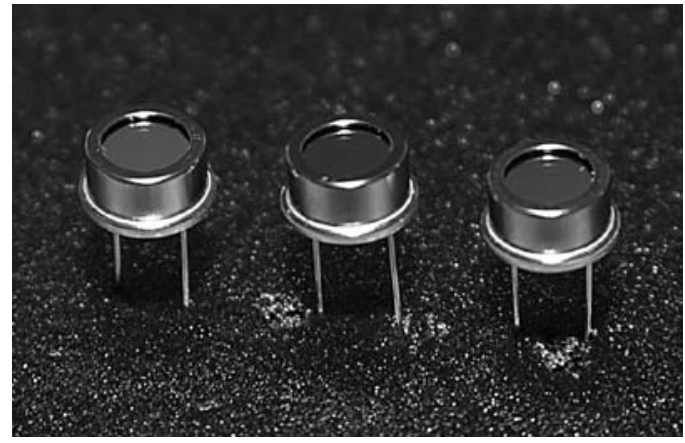

(a)

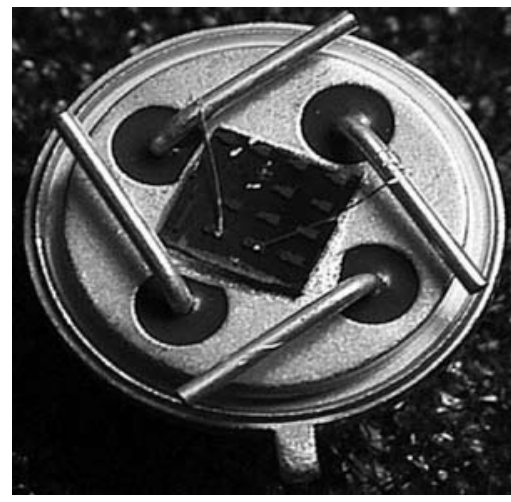

(b)

Fig. 14. (a) GaN UV sensor ${ }^{(32)}$ and (b) photographs of two-terminal GaN Schottky diode for gas sensing applications (packaged device). ${ }^{(33)}$

The development of GaN substrates is being strongly supported by the positive attitude of major material manufacturers towards GaN substrates. This article reviewed innovative nonpolar/semipolar GaN devices, which will drive the demand for bulk GaN substrates, and discussed the current issues in manufacturing $\mathrm{GaN}$ substrates, focusing on substrate size expansion, growth method of bulk $\mathrm{GaN}$, and processing of $\mathrm{GaN}$ wafers.

\section{Acknowledgements}

A part of this work was supported by JSPS KAKENHI Grant (Grant-in-Aid for Scientific Research(S)) Number 24226005.

\section{References}

1 Nikkei Electronics (2011.12. 21), p. 67.

2 Y. Takeda: Ceram. Jpn. 46 (2011) 616 (in Japanese).

3 H. Amano, N. Sawaki, I. Akasaki and Y. Toyoda: Appl. Phys. Lett. 48 (1983) 427.

4 S. Nakamura: Jpn. J. Appl. Phys. Part II 30 (1991) L1705.

5 S. Nakamura, T. Mukai, M. Senoh and N. Iwasa: Jpn. J. Appl. Phys. Part II 31 (1992) L139.

6 S. Nakamura, T. Mukai and M. Senoh: Jpn. J. Appl. Phys. Part II 32 (1993) L16.

7 R. Haitz and J. Y. Tsao: Phys. Status Solidi A 208 (2008) 17.

8 H. Asamizu, M. Saito, K. Fujito, J. S. Speck, S. P. DenBaars and S. Nakamura: Appl. Phys. Express 1 (2008) 091102.

9 M. Neno, K. Katayama, T. Ikegami and T. Nakamura: Oyo Butsuri 81 (2012) 497 (in Japanese).

10 S. Nakamura: Nakamura Inhomogeneous Crystal, http://www.jst.go.jp/erato/project/nfk_P/ nfk_P-j.html. 
11 B. A. Haskell, F. Wu, M. D. Craven, S. Matsuda, P. T. Fini, T. Fujii, K. Fujito, S. P. DenBaars, J.S. Speck and S. Nakamura: Appl. Phys. Lett 83 (2003) 644.

12 B. A. Haskell, T. J. Baker, M. B. McLaurin, F. Wu, P. T. Fini, S. P. DenBaars, J. S. Speck and S. Nakamura: Appl. Phys. Lett. 86 (2005) 111917.

13 T. J. Baker, B. A. Haskell, F. Wu, P. T. Fini, J. S. Speck and S. Nakamura: Jpn. J. Appl. Phys. 44 (2005) L920.

14 A. Chakraborty, S. Keller, C. Meiner, B. A. Haskell, P. Waltereit, S. P. DenBaars, S. Nakamura, J. S. Speck and M. K. Mishra: Appl. Phys. Lett. 86 (2005) 031901.

15 A. Chakraborty, B. A. Haskell, S. Keller, J. S. Speck, S. P. DenBaars, S. Nakamura and U. K. Mishra: Jpn. J. Appl. Phys. 44 (2005) L173.

16 K. Okamoto, H. Ohta, D. Nakagawa, M. Sonobe, J. Ichihara and H. Takasu: Jpn. J. Appl. Phys. 45 (2006) L1197.

17 M. C. Schmidt, K. C. Kim, H. Sato, N. Fellows, H. Masui, S. Nakamura, S. P. DenBaars and J. S. Speck: Jpn. J. Appl. Phys. 46 (2007) L126.

18 A. Tyagi, H. Zhong, N. Fellows, M. Iza, J. S. Speck, S. P. DenBaars and S. Nakamura: Jpn. J. Appl. Phys. 46 (2007) L129.

19 http://www.sei.co.jp/newsletter/2010/12/5a.html.

20 http://www.m-kagaku.co.jp/products/business/electron/gan/index.html.

21 R. Dwilinski, R. Doradzinski, J. Garczynski, L.P. Sierzputowski, A. Puchalski, Y. Kanbara, K. Yagi, H. Minakuchi and H. Hayashi: J. Cryst. Growth 310 (2008) 3911.

22 E. Letts, T. Hashimoto, M. Ikari and Y. Nojima: J. Cryst. Growth 350 (2012) 66.

23 R. Dwilinski, R. Doradzinski, J. Garczynski, L. Sierzputowski, R. Kucharski, M. Zaja, M. Rudzinski, R. Kudrawiec, J. Serafinczuk and W. Strupinski: J. Cryst. Growth 312 (2010) 2499.

24 H. Yamane, M. Shimada, S. J. Clarke and F. J. DiSalvo: Chem. Mater. 9 (1997) 413.

25 Y. Mori, Y. Kitaoka, M. Imade, N. Miyoshi, Y. Yoshimura and T. Sasaki: Phys. Status Solidi A 207 (2010) 1283.

26 F. Kawamura, M. Morishita, M. Tanpo, M. Imade, M. Yoshimura, Y. Kitaoka, Y. Mori and T. Sasaki: J. Cryst. Growth 310 (2008) 3946.

27 H. Amano: Oyo Buturi I 81 (2012) 455.

28 Y. Mori, Y. Kitaoka, M. Imade, N. Miyoshi, Y. Yoshimura and T. Sasaki: Phys. Status Solidi C 8 (2011) 1445.

29 T. Doi, I. Marinescu and S. Kurokawa: Advances in CMP Polishing Technologies (Elsevier, 2011) p.16.

30 T. Doi, H. Aida, K. Koyama and H. Takeda: GaN Power Devices (Sci. \& Technol. Co., 2012) p.141 (in Japanese).

31 T. K. Doy: Sens. Mater. 3 (1989) 153.

32 H. Aida, H. Takeda, K. Koyama, H. Katakura, K. Sunakawa and T. Doi: J. Electrochem. Soc. 158 (2011) H1206.

33 D. DeNardis, T. Doi, B. Hiskey, K. Ichikawa, D. Ichikawa, and A. Philipossian: J. Electrochem. Soc. 152 (2005) G824.

34 http://www.kyosemi.co.jp/.

35 B. S. Kang, H. T. Wang et al.: Sensors 6 (2006) 643. 
About the Author

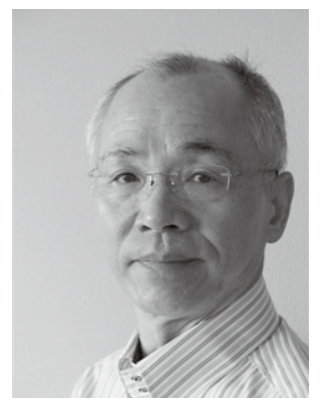

Toshiro Karaki Doi is currently a Professor in the Art, Science \& Technology Center (KASTEC) at Kyushu University, Japan. After graduating from Yamanashi University, Dept. of Engineering in 1971, and finishing his graduate study on precision engineering in 1973, he joined Nippon Telegraph and Telephone Public Corporation (NTT) in the same year. He earned his $\mathrm{PhD}$ in Polishing Technology from the University of Tokyo in 1985. He left NTT in 1988 and joined Saitama University. While in Saitama University, he served as visiting professor at the University of Arizona in USA from 2003 to 2005 . He left Saitama University in 2007 to work in Kyushu University. He is currently a professor emeritus of Kyushu University as well as of Saitama University, and is actively engaged in the research and development of ultraprecision process of crystal materials for the realization of a green device society as a professor in KASTEC, Kyushu University. His research covers precision processing including CMP technology for functional materials. He has published several books and more than 300 papers in Japan and abroad. He is the inventor or coinventor of more than 190 patents. He has been awarded academic prizes more than 10 times. He is a fellow, a distinguished chairman of the Planarization CMP Committee of JSPE, a chairman of the 136 Committee on Future-Oriented Machining of JSPS, Electrochemical Society, and a member of other national and international associations. 